\title{
SCHEDULE MANAGEMENT PROCESS MODEL BASED ON CSDM
}

\author{
Ryu, Han-guk, \\ PhD. Candidate, Dept. of Architecture, School of Engineering, Seoul National University \\ hglyu@cricmail.net \\ Lee, Hyun-soo, \\ Professor, Dept. of Architecture, School of Engineering, Seoul National University
}

\begin{abstract}
The duration of a construction project must be an important item in construction contracts. If a contractor can work in the planned parameter, the contractor can finish the construction project in a timely manner. However, when construction industry is compared to other industries, it is difficult to complete a construction project in which many construction trades participate during the construction phase. In most cases, there are numerous impact factors that impact a construction process and hinder its timely completion. Those impact factors can be categorized construction schedule risk, productivity, constraints and so forth. The scheduler must consider the impact factors to plan the construction project schedule. But, many studies or methodologies or programs on planning the construction schedule have been focused on the result of works. So, this study proposes the schedule management process model based on CSDM (Construction Schedule Data Mart) considering data warehousing, MOLAP (and case-base reasoning.
\end{abstract}

Keywords: CSDM(Construction Schedule Data Mart), Schedule Process, Impact Factor, Schedule Risk, CBR(Case-Based Reasoning)

\section{INTRODUCTION}

The duration of a construction project must be an important item in construction contracts. If a contractor can work in the planned parameter, the contractor can finish the construction project in a timely manner. However, when construction industry is compared to other industries, it is difficult to complete a construction project in which many construction trades participate during the construction phase. In most cases, there are numerous impact factors that impact a construction process and hinder its timely completion. Those impact factors can be categorized construction schedule risk, productivity, constraints and so forth. So, the scheduler must consider the impact factors to plan the construction project schedule. But, many studies or methodologies or programs on planning the construction schedule have been focused on the procedure and the result of works. This study focused on the process of construction schedule management instead of the result of construction project. This study involves all of the construction schedule management during planning and construction.

So, this study proposes the schedule management process model based on CSDM(Construction Schedule Data Mart) considering impact factors and case-based reasoning.

\section{PROCESS MODEL OF SCHEDULE MANAGEMENT}

\section{1 the objective of schedule management}

The objective of schedule management is exteriorly to succeed the construction project during the contracted construction project period and internally to do organizational own effort within limited resources such as cost, material, machine, labors, method etc., to meet the contracted period. The organization structure of schedule management is shown in fig.1. It is important to cooperate systematically the schedule management of the horizontal-vertical organization.

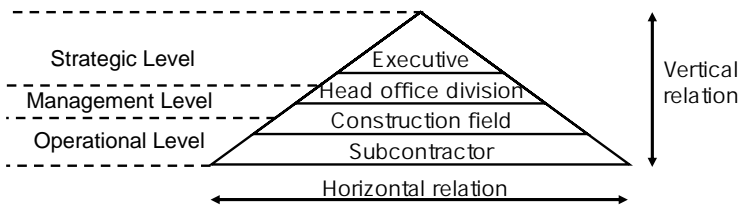

Figure 1. Organization structure

The work scope and decision items are different according to the level as follows.

(1) Strategic level : making schedule management strategy according to the company's strategy.

(2) Management level : supporting the operational level and making the workable construction situation. (3) Operational level : making more workable construction situation than management level, checking the work process and outcomes, performing the work, comparing the work performance with work schedule and reflecting the difference of work performance and work schedule to the following work plan, making a schedule meeting and so forth. 


\section{2 project planning}

Project plan is the function of selecting the enterprise objectives and establishing the policies, procedures, and programs necessary for achieving them. Project planning must be systematic, flexible enough to handle unique activities, disciplined through reviews and controls, and capable of accepting multifunctional inputs (Kerzner(1998)). Project plan is the document for the project work involving all works from the start of project to the component of the future works. Popescu and Charoenngam (1995) described the project planning and control cycle in fig.2.

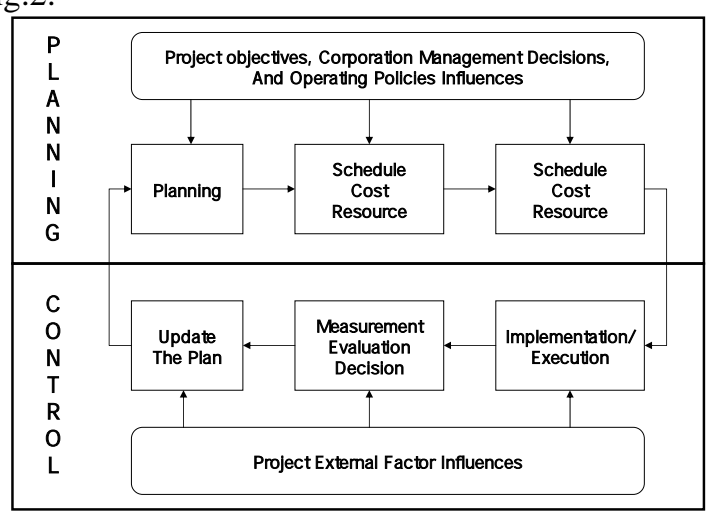

Figure 2. Project planning and control cycle Construction project is the dynamic entity to be actively managed to the internal and external conditions. The construction project schedule plan is composed of project planning and control considering such dynamic conditions. As shown in fig.2., project planning is made based on operation' strategy and objective of the project management. The project planning are controlled during implementation/execution, measurement, evaluation, and feedback considering project external factor influences.

Table 1. shows the project planning objectives and the means to the objective.

Table 1. Project planning objectives and means

\begin{tabular}{|c|c|}
\hline ing objective & Means \\
\hline ement confirmation, & $\begin{array}{l}\text {-contract review and } \\
\text { implementation } \\
\text {-time cost trade-off } \\
\text { decision } \\
\text {-master plan }\end{array}$ \\
\hline $\begin{array}{l}\text { special } \\
\text { nent confirmation }\end{array}$ & $\begin{array}{l}\text { contract review and } \\
\text { implementation }\end{array}$ \\
\hline $\begin{array}{l}\text { Work scope and flexible } \\
\text { relation } \\
\text { establishment }\end{array}$ & $\begin{array}{l}\text {-quaterly, monthly, } \\
\text { and weekly schedule }\end{array}$ \\
\hline $\begin{array}{l}\text { Resource } \\
\text { efficiency }\end{array}$ & $\begin{array}{l}\text { resource } \\
\text { plan }\end{array}$ \\
\hline $\begin{array}{lr}\begin{array}{l}\text { Responsibility, authority, } \\
\text { work }\end{array} & \text { relationship } \\
\text { establishment } & \\
\end{array}$ & $\begin{array}{l}\text { uct review } \\
\text { uction plan }\end{array}$ \\
\hline $\begin{array}{ll}\text { Work planning form } \\
\text { confirmation }\end{array}$ & $\begin{array}{l}\text { making operation's } \\
\text { standard form and }\end{array}$ \\
\hline
\end{tabular}

\begin{tabular}{|l|l|}
\hline & manual \\
\hline $\begin{array}{l}\text { Consensus of opinion, } \\
\text { Making participant's } \\
\text { responsibility }\end{array}$ & $\begin{array}{l}\text {-contract review } \\
\text {-schedule meeting }\end{array}$ \\
\hline Making detail drawing & $\begin{array}{l}\text {-specification } \\
\text {-operation's standard }\end{array}$ \\
\hline Time control & $\begin{array}{l}\text {-performance } \\
\text { measurement } \\
\text {-work control and } \\
\text { feedback }\end{array}$ \\
\hline $\begin{array}{l}\text { Information gathering } \\
\text { method }\end{array}$ & $\begin{array}{l}\text {-input and output } \\
\text { information definition }\end{array}$ \\
\hline
\end{tabular}

Table 2. shows the project control objectives and the means to the control.

Table 2. Project control objectives and means

\begin{tabular}{|l|l|}
\hline $\begin{array}{l}\text { Project control } \\
\text { objectives }\end{array}$ & Means \\
\hline $\begin{array}{l}\text { Comparing work } \\
\text { performance with work } \\
\text { plan }\end{array}$ & -performance graph \\
\hline $\begin{array}{l}\text { Verification of optimal } \\
\text { work pattern }\end{array}$ & $\begin{array}{l}\text {-verification of } \\
\text { maximum productivity }\end{array}$ \\
\hline $\begin{array}{l}\text { Decision of specific } \\
\text { work pattern }\end{array}$ & -reschedule \\
\hline Recovery time & $\begin{array}{l}\text {-acceleration or delay } \\
\text { and so forth. }\end{array}$ \\
\hline
\end{tabular}

\section{IMPACT FACTORS ON DURATION AND THE UTILIZATION OF CSDM}

\subsection{CSDM (construction scheduling data mart)}

Construction schedule data and information can be managed through the network between server and client. Fig.3. shows the life cycle of the CSDM (construction scheduling data mart).

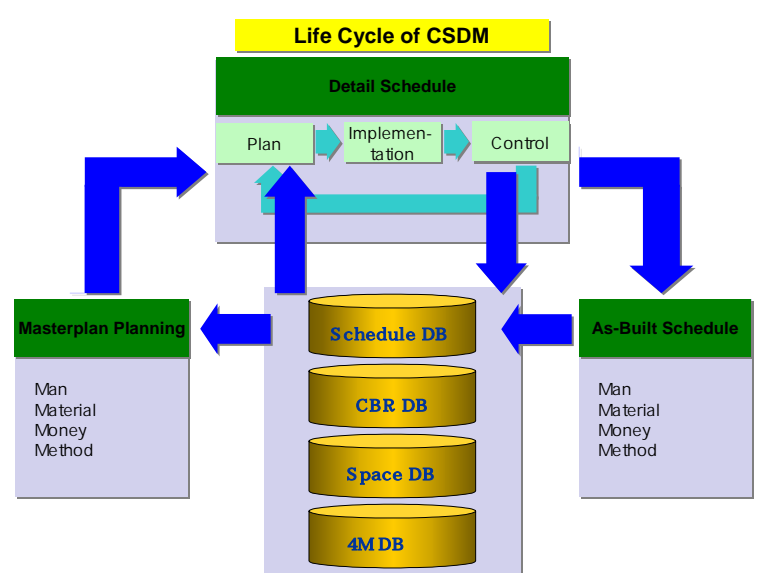

Figure 3. Life Cycle of CSDM

Construction schedule master plan is drawn before construction by using the accumulated information of the CSDM, the detail construction schedule is drawn during construction and confirm the work performance. The accumulating process of the schedule related information is repeated periodically as a quarter, month and week. After completion of 
the construction project, the construction schedule related information is accumulated for the using of the following similar project scheduling.

\section{2 system structure of CSDM}

The schedule related information is accumulated from the company's operating system such as ERP, PMIS, daily report system, construction schedule system to database of the CSDM through ODS(operational data store). The ODS serves as a point of integration for operational systems. In many cases, these ODS are implemented to better support one-to-one customer relationships in the order entry or customer service function. The ODS should be a subject-oriented (schedule-oriented in this study), integrated, frequently updated store of detailed data to support transaction systems with integrated data. Any detailed data used for decision support should simply be viewed as the lowest atomic level of the data warehouse.

The cumulated information of CSDM can be used through CBR (Case-Based Reasoning) and MOLAP (Multidimensional On-Line Analytical Processing) to make a schedule related decision. Fig. 4 shows the system structure of CSDM.

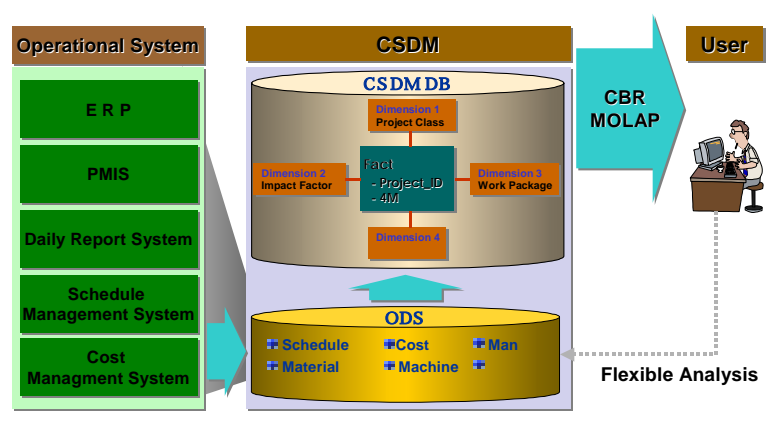

Figure 4. System Structure of CSDM

\subsection{MOLAP}

Kimball (1998) described that MOLAP (Multidimensional On-Line Analytical Processing) is a set of user interfaces, applications, and proprietary database technologies that have a strongly dimensional flavor. Since the MOLAP tools were built for decision support, they tend to have much stronger analytical functions built into the engine. Some of the MOLAP tools allow both reads and writes to the data, which makes them very important for applications like schedule forecasting. MOLAP engines, also known as multidimensional database management system, are database management systems that are designed to provide specialized support for dimensional analysis such as project class dimension, impact factor dimension, work package dimension and so forth. MOLAP engines can make an excellent data mart platform for schedule related requirements that can be met by a fairly simple star schema-that is, relatively few dimensions, each with relatively few rows. The most significant benefits of using a MOLAP engine is the end user query performance. Facts are prestored at all valid combinations of the dimensions.

\section{PRECONSTRUCTION PLANNING BY USING CBR}

\section{1 the usage of $C B R$ (case-based reasoning)}

CBR can be regarded both as a cognitively sound modeling approach for explaining human problem solving in domains where experience plays an important role (Strube and Janetzko (1990)). It is especially appealing to those professionals who solve problems by recalling what they did in similar situations that happened in the past. The basic idea of CBR (case-based reasoning) is to adapt solutions that have been used to solve old problems for use in solving new problems (Turban and Aronson (2001)). A case is the primary knowledge-base element in a case-based reasoning application. It defines a situation or problem in terms of natural language descriptions and answers to questions and associates with each situation a proper business action. Scripts can be constructed from historical cases that reflect human experience. The experience can be that of the decision makers or of others. CBR is the essence of how people reason from experience. CBR has been proposed as a more psychologically plausible model of the reasoning of an expert than a rule-based model. A theoretical comparison of the two was made by Riesbeck and Schank (1989), and a summary is provided in Table 3.

Table 3. Comparison of Case-based and Rule-based Reasoning

\begin{tabular}{|c|c|c|}
\hline Criterion & $\begin{array}{l}\text { Rule-based } \\
\text { Reasoning }\end{array}$ & $\begin{array}{l}\text { Case-based } \\
\text { Reasoning }\end{array}$ \\
\hline $\begin{array}{c}\text { Knowledge } \\
\text { unit }\end{array}$ & Rule & Case \\
\hline Granularity & Fine & Coarse \\
\hline $\begin{array}{l}\text { Knowledge } \\
\text { acquisition } \\
\text { units } \\
\end{array}$ & $\begin{array}{l}\text { Rules, } \\
\text { hierarchies }\end{array}$ & $\begin{array}{l}\text { Cases, } \\
\text { hierarchies }\end{array}$ \\
\hline $\begin{array}{l}\text { Explanation } \\
\text { mechanism }\end{array}$ & $\begin{array}{l}\text { Backtrack of } \\
\text { rule firings }\end{array}$ & $\begin{array}{l}\text { Precedent } \\
\text { cases }\end{array}$ \\
\hline $\begin{array}{c}\text { Characteristic } \\
\text { output }\end{array}$ & $\begin{array}{ll}\text { Answer } & \text { and } \\
\text { confidence } & \\
\text { measure } & \\
\end{array}$ & $\begin{array}{l}\text { Answer and } \\
\text { precedent cases }\end{array}$ \\
\hline $\begin{array}{l}\text { Knowledge } \\
\text { transfer across } \\
\text { problems }\end{array}$ & $\begin{array}{ll}\text { High } & \text { if } \\
\text { backtracking; } & \\
\text { linear } & \text { if } \\
\text { deterministic } & \end{array}$ & Low \\
\hline $\begin{array}{l}\text { Speed as a } \\
\text { function of } \\
\text { knowledge } \\
\text { base size }\end{array}$ & $\begin{array}{l}\text { Exponential if } \\
\text { backtracking; } \\
\text { linear } \\
\text { deterministic }\end{array}$ & $\begin{array}{l}\text { Logarithmic if } \\
\text { index tree is } \\
\text { balanced }\end{array}$ \\
\hline $\begin{array}{c}\text { Domain } \\
\text { requirements }\end{array}$ & $\begin{array}{l}\text { Domain } \\
\text { vocabulary }\end{array}$ & $\begin{array}{l}\text { Domain } \\
\text { vocabulary }\end{array}$ \\
\hline & Good set & Database \\
\hline
\end{tabular}




\begin{tabular}{|c|l|l|}
\hline & inference rules & example cases \\
\hline & $\begin{array}{l}\text { Either few rules } \\
\text { or rules apply } \\
\text { sequentially }\end{array}$ & $\begin{array}{l}\text { Stability } \text { (a } \\
\text { modified good } \\
\text { solution is } \\
\text { probably still } \\
\text { good) }\end{array}$ \\
\hline Advantages & $\begin{array}{l}\text { Domain mostly } \\
\text { obeys rules }\end{array}$ & $\begin{array}{l}\text { Many } \\
\text { exceptions to } \\
\text { rules }\end{array}$ \\
\hline & $\begin{array}{l}\text { Potentedially use of } \\
\text { optimal answers }\end{array}$ & $\begin{array}{l}\text { Rapid response } \\
\text { knowledge } \\
\text { acquisition } \\
\text { Explanation by } \\
\text { examples }\end{array}$ \\
\hline Disadvantages & $\begin{array}{l}\text { Computationally } \\
\text { expensive }\end{array}$ & $\begin{array}{l}\text { Suboptimal } \\
\text { solutions }\end{array}$ \\
\hline & $\begin{array}{l}\text { Long } \\
\text { development } \\
\text { time }\end{array}$ & $\begin{array}{l}\text { Redundant } \\
\text { knowledge } \\
\text { base }\end{array}$ \\
\hline Black-box & answers & \\
\hline
\end{tabular}

CBR has proved to be an extremely effective approach in complex cases (Kolonder (1993)). According to Riesbeck and Schank (1989), the basic justification for the use of this approach is that human thinking does not use logic (or reasoning from first principles).

More over, CBR has been used to create numerous applications in a wide range of domains, including financial analysis, risk assessment, technical maintenance, process control, quality control, medical diagnosis, software support systems, forecasting, planning, design, classification of objects, photo-interpretation, and real estate appraisal (Althoff and Bartsch-Spörl (1996) )

Likewise, many human schedulers create schedules by reusing past similar schedules (Dzeng and Tommelein (2004)). It is difficult for a human project planner to newly generate a project network without referring to any previous cases because the amount of required knowledge is too large and complex. Therefore, human experts usually look for a similar previous project network for reference and get previous human expert knowledge by referencing previous similar networks (Lee et al (1998)).

The retrieval and reuse of similar schedules are subjective and experience-based. Constructing a new schedule is a matter of finding suitable network fragments from previous schedules and adapting these for reuse. Traditional scheduling tools provide only limited features to facilitate such reuse . For example, Primavera Project Planner (P3 (1999)) allows the user to define and reuse the fragnet, a subnetwork composed of activities with fixed names, duration, and sequential relationships between each other. A limitation of $\mathrm{P} 3$ is that the fragnet has no relationships with the data pertaining to the project it was initially created for, and can be retrieved only by its name. Modification of the fragnet may be required before it is used. P3 provides features that facilitate the addition of a prefix or a suffix to all activity numbers, or specific text or a number to all activity names. However, the added values have to be specified manually even though many of them could have been figured out by a computer had the relationships between the fragnet and the project data been available (Dzeng and Tommelein 2004).

\subsection{Knowledge management of Conpla-CBR}

Dubitzky (1999) proposed that case-based reasoning process as a knowledge management process. The construction schedule based on the CBR can be managed as a knowledge management. Conpla-CBR can be categorized largely into two items : case accumulation and case utilization. Fig. 5 shows the knowledge management of Conpla-CBR.

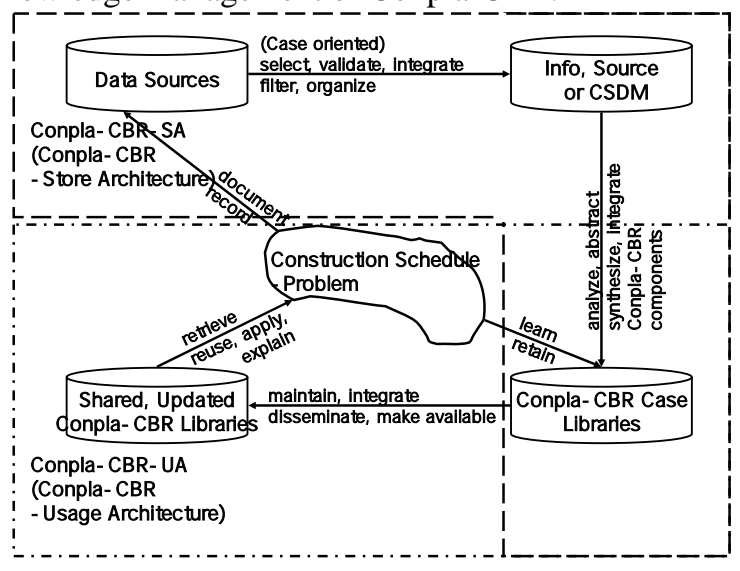

Figure 5. Knowledge management of Conpla-CBR

The part shown in dotted line is the accumulation part of construction schedule case such as ConplaCBR-SA, info, Source or CSDM and Conpla-CBR Cases Libraries. The construction schedule data or information are selected, validated and integrated from the data source to information, Source or CSDM through the filtering and organizing method. The information, source or the data of CSDM are analyzed and abstracted from the information, source or CSDM to the Conpla-CBR case libraries through synthesizing, integrating and component method in the accumulation part.

On the other hand, the part shown in dashed-dotted line is the utilization part of construction schedule case such as Conpla-CBR Cases Libraries and Shared, Updated Conpla-CBR Case Libraries. The information or data of Conpla-CBR Case Libraries case are maintained and integrated to the Shared, Updated Conpla-CBR Case Libraries through disseminating method and available method.

Data or information from the construction schedule problem (real world problem) are documented or recorded to the Data Sources and learned or retained to the Conpla-CBR Libraries. Therefore the knowledge management of Conpla-CBR is that the case information from the Shared, Updated Conpla- 
CBR Case Libraries are retrieved, reused, applied, and explained to solve the construction schedule problems.

\section{3 the cycle of Conpla-CBR}

The cycle of Conpla-CBR is shown graphically in fig. 6 and (revised from Aamodt and Plaza (1994)).

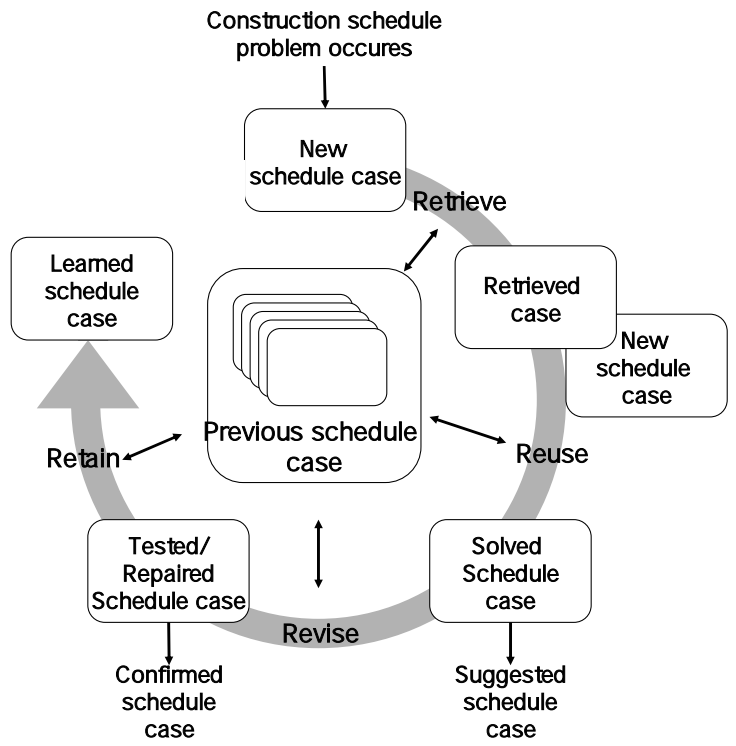

Figure 6. the cycle of Conpla-CBR

The first sub task is to retrieve one or more similar schedule cases from the schedule case library where former construction project schedule experiences are stored in the form of previous schedule cases. The main hypothesis behind CBR is quite simply "similar construction schedule problems have similar construction schedule solutions", "you can reuse the schedule solution of a similar schedule problem in order to solve your actual problem". Based on this hypothesis, the second sub task is to reuse the similar construction schedule case. But the construction project situations are different case by case. So the third sub task is to revise the schedule case just as much as necessary. The last step stores valuable confirmed construction schedule solutions for further reuse. This step is called retain and completes the construction schedule experience feedback loop that is a necessary prerequisite for enabling a system to learn form construction project experience (Althoff and Bartsch-Spörl (1996)).

\section{4 the process of Conpla-CBR}

The process of Conpla-CBR is shown graphically in fig. 8 and (revised from Turban and Aronson (2001)). Boxes represent Conpla-CBR processes, and ovals represent knowledge structure.

The major steps in the Conpla-CBR process are described in the following list.

(1) Assign indexes : features of the new construction schedule event are assigned as indexes characterizing the construction situation or outline.

(2) Retrieve : the indexes are used to retrieve a similar past schedule case from CSDM. The past schedule case contains the prior construction project schedule case.

(3) Modify : the old schedule case is modified to conform to the new construction project situation, resulting in a proposed construction project schedule.

(4) Test : the proposed construction schedule is tried out in construction field. It succeeds either fully or partially.

(5) Assign and store : if the proposed construction schedule succeeds, then assign indexes and store a construction schedule. The successful construction schedule or plan is then incorporated into the CSDM.

(6) Explain, repair, and store : if the construction schedule solution fails, then explain the failure, repair the work plan. The explanation process identifies the source of the construction schedule problem. The predictive features of the problem are incorporated into the indexing rules to anticipate construction schedule problem in the future. The partially succeeded construction plan is repaired to fix the construction schedule problem and the revised schedule is then stored for the using of following construction project.

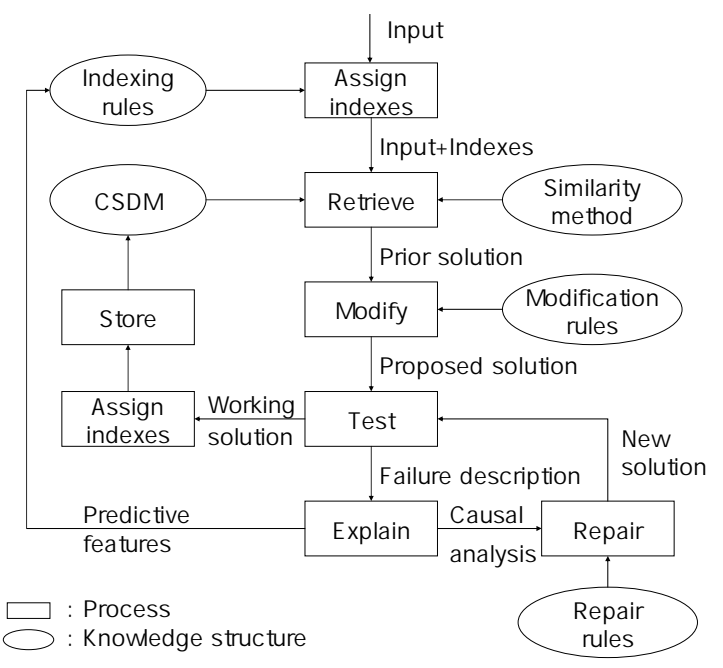

Figure 8. the process of case-based reasoning

To support of this process, the types of knowledge structures, represented by ovals, are described in the following lists.

(1) Indexing rules : indexing rules identify the predictive features in the input that provide appropriate indexes in the CSDM. Determining the significant input features is a persistent problem.

(2) CSDM : CSDM is the episodic memory, which comprises the database of construction schedule case experience.

(3) Similarity metrics : if more than one case is retrieved from episodic memory or CSDM, the similarity metrics can be used to decide which schedule case is more like the current 
construction project situation. Modification rules : No old construction schedule case is going to be an exact match for a new construction project situation or outline. The old construction schedule case must be modified to fit. So the knowledge about what kinds of impact factors on construction schedule can be changed and how to change them must be recognized.

(4) Repair rules : Once users identify and forecast an expected failure, user must try to alter the construction schedule or plan to fit the new construction project situation.

\section{Acknowledgments}

The authors would like to thank the Korea Institute of Science and Technology Evaluation and Planning (Grant M1-0104-00-0274) for their contributions to this research.

\section{REFERENCES}

[1] Aamodt, A. and Plaza, E., "Case-Based Reasoning:Foundational Issues, Methodological variations, and system approaches", AI Communications, IOS Press, Vol.7, No.1, pp.39-59, 1994

[2] Althoff, K., and Bartsch-Spörl, B., "Decision support for case-based applications", Wirtschaftsinformatick 38, 1/96, pp6-14, 1996

[3] Dzeng, R. and Tommeleing, I.D., "Product modeling to support case-based construdtion planning and scheduling, Automation in Construction 13, pp.341-360, 2004

[4] Dubitzky, W., Büchner, A.G., and Azuaje, F.J. Viewing knowledge management as a Case-based reasoning application, University of Ulster, 1999

[5] Kimball, R., The data warehouse lifecycle toolkit, John Wiley \& Sons, Inc., 1998

[6] Kolonder, J., Case-based Reasoning. Mountain View, CA:Morgan Kaufmann, 1993

[7] Lee, K.J., Kim, H.W., Lee, J.K., and Kim,T.H., "Case- and constraint-based project planning for apartment construction”, American Association for Artificial Intelligence, pp.13-24

[8] Primavera Systems, Primavera Project Planner Reference, Manual-Version 3.0, Primavera Systems, Bala Cynwyd, PA, pp. 58-60, 1999.

[9] Riesbeck, C.K., and Schank, R.L. Inside Casebased Reasoning, Hillsdale, NJ:Erlbaum Associates., 1989
[10] Strube, G., and Janetzko, D., "Episodisches Wissen und fallbasiertes Schließen: Aufgaben für die Wissensdiagnostik und die Wissenspsychologie." Schweizerische Zeitschrift für Psychologie, vol.49 no.4, pp211-221, 1990

[11] Turban, E. and Aronson, J.E., Decision support systems and intelligent system, Prentice Hall, 2001 